\title{
Original Article (short paper) \\ Translation and validation of the perceived locus of causality questionnaire (PLOCQ) in a sample of portuguese physical education students
}

\author{
Diogo S. Teixeira ${ }^{1}$, Diogo Monteiro ${ }^{2,4}$, Eliana Carraça ${ }^{1,3}$, António L. Palmeira ${ }^{1,3}$ \\ ${ }^{1}$ Universidade Lusófona de Humanidades e Tecnologias, ULHT, Faculty of Physical Education and Sport, Lisboa, Portugal; ${ }^{2}$ Es- \\ cola Superior de Desporto de Rio Maior, ESDRM-IPSANTARÉM, Rio Maior, Portugal; ${ }^{3}$ Universidade de Lisboa, Interdisciplina- \\ ry Center for the Study of Human Performance, CIPER, Faculty of Human Kinetics, Lisboa, Portugal; ${ }^{4}$ Universidade de Trás- \\ os-Montes e Alto Douro, Centro de Investigação em Desporto, Saúde e Desenvolvimento Humano, CIDESD, Vila Real, Portugal
}

\begin{abstract}
Aim: This study main aim was to translate and validate one of the most used SDT-based instruments to assess motivation in PE classes, the Perceived Locus of Causality Questionnaire (PLOCQ), to the Portuguese context. Method: Sample was composed of 652 boys $(M=15.4$ years; $S D=1.90)$ and 702 girls $(M=15.47$ years; $S D=1.95)$, enrolled in physical education classes in several Portuguese schools. Results: The analysis provided support for a five factors and 18 items model, after excluding two items $\left(\chi^{2}=491.473, d f=125, p=<.001, \mathrm{SRMR}=.062, \mathrm{NNFI}=.908\right.$, $\mathrm{CFI}=.924, \mathrm{RMSEA}=.067,90 \%$ CI .061-.073). Sample and gender invariance procedures were made to ensure proper psychometric validation. Results presented support for the model in both gender and calibration/validation samples. Conclusion: This study suggests that PLOCQ with five factors and 18 items has good psychometric properties and can be used to assess contextual motivation towards PE in the Portuguese context.
\end{abstract}

Keywords: psychological assessment; confirmatory factor analysis; self-determination theory; multi-group analysis; physical education.

\section{Introduction}

Motivation in Physical Education (PE) classes has been a focus of study and concern on the part of several researchers. Given the characteristics of the class and students, physical education teachers need to better understand how to improve their intervention, helping students achieving the warranted effects of PE. This can pose a difficult task when contextual motivation of students changes across time ${ }^{1}$.

Self-Determination Theory $\left(\mathrm{SDT}^{2}\right)$ has been one of the main frameworks used to study motivational processes throughout the last 30 years. This theory includes several mini-theories. One of its mini-theories (Cognitive Evaluation) postulates that two types of motivation influence one's behavior. When someone is doing an activity for the inherent pleasure or interest, it is considered that the person is intrinsically motivated; on the opposite side, performing an activity for instrumental reasons, to avoid disapproval or obtain separable outcomes characterizes an extrinsically motivated person. If an individual does not perceive a worthwhile reason to participate in an activity, then there is an absence of intrinsic or extrinsic motivation - defined in SDT as amotivation ${ }^{3,4}$.

In Deci and Ryan ${ }^{2,5}$ seminal work, it has been proposed that the different types of motivation are expressed in a continuum that reflects the individual's level of self-determination. According to the Organismic Integration Theory, extrinsic motivation is composed of four behavioral regulations increasing in their degree of self-determination or autonomy. The less self-determined form of extrinsic motivation is external regulation, which reflects the influence of external pressures or rewards on the behavior. Next, introjected regulation reflects self-imposed pressures like guilt, shame or ego protection. These two behavioral regulations express a form of external control in the individual behavior. Identified regulation, which refers to the recognition and acceptance of the importance of a behavior, and integrated regulation, manifesting the pursuit of an activity because it is in line with one's core values and sense of self, represent a gradual transition to more autonomous forms of motivation. In SDT, these regulatory mechanisms reflect a degree of internalization of the behavior, facilitating the understanding of exercise behavior in several contexts. Previous studies have showed that more autonomous forms of motivation are positively associated with exercise behavior and continuous adherence ${ }^{6}$, higher levels of concentration in $\mathrm{PE}^{7}$, better affective outcomes ${ }^{8,9}$ and preference to engage in challenging tasks ${ }^{7,8}$.

Throughout the years, $\mathrm{SDT}^{2,10}$ has sustained the development of several instruments to assess student's perceptions about their motivation ${ }^{11}$. However, these instruments are created and validated in a particular language and culture and may not accurately measure what is intended after being translated and/or adapted to a new setting, culture or language. Despite cross-cultural validations and the universality of SDT principles, little attention has been given to the validity scores of some of the most popular SDT-based measurement instruments ${ }^{12}$.

One of these instruments is the Perceived Locus of Causality Questionnaire (PLOCQ), which is used to assess contextual motivation towards PE. This instrument was initially developed by Goudas, Biddle and Fox ${ }^{13}$ through an adaptation of the SelfRegulation Questionnaire developed by Ryan and Connell ${ }^{14}$. Their aim was to create a scale that encompassed the full range of the SDT behavioral regulation spectrum (except for integrated 
regulation). To measure amotivation, the Vallerand, Pelletier, Blais, Brière, Senécal, Vallières ${ }^{15}$ subscale of the academic Motivation Scale was used.

Psychometric testing supported the reliability and validity of the PLOCQ subscales ${ }^{7,16,17}$. Yet, some issues with the internal consistency of introjected regulation scores and the discriminant validity of identified regulation and intrinsic motivation scores were reported $^{7,16}$. Posteriorly, Lonsdale, Sabiston, Taylor, Ntoumanis ${ }^{12}$ provided further psychometric analysis and cross-cultural validation of the instrument. Currently, the PLOCQ is considered as a valid and useful instrument to assess what it proposes.

In the Portuguese context, PLOCQ has been widely used in the PE context in the last years. However, to our knowledge, no psychometric validation was made to ensure its feasibility in this particular language and context, an overly due problem in this field of study. Therefore, this study sought to translate and validate one of the most used SDT-based instruments to assess motivation in PE classes, the Perceived Locus of Causality Questionnaire (PLOCQ), to the Portuguese context. Psychometric proprieties and invariance across gender were evaluated to ensure proper instrument feasibility.

\section{Method}

\section{Participants}

Two independent samples of PE students were used in this study to ensure the robustness of the measurement instrument in a sample of the same population.

The first set of participants consisted of 699 students and represented the calibration sample, with ages comprised between 12 and 23 years old $(M=15.49 ; \mathrm{SD}=1.93)$, and enrolled in two $\mathrm{PE}$ classes/week (135 min total). The validation sample was composed of 655 students, with ages between 12 and 23 years old $(M=15.47$; $\mathrm{SD}=1.88$ ), and had the same amount of $\mathrm{PE} /$ week than previous sample. The global sample comprised 652 boys $(M=15.4$ years; $\mathrm{SD}=1.90)$ and 702 girls $(\mathrm{M}=15.47$ years; $\mathrm{SD}=1.95)$.

\section{Measures}

The Perceived Locus of Causality questionnaire ${ }^{12}$ (PLOCP) was translated and adapted to the Portuguese context. The PLOCPp consists of 20 items with a seven-point Likert scale, ranging from 1 ("Strongly Disagree") to 7 ("Strongly Agree"). The items are grouped into five factors (with four items each), which reflect the behavioral regulations encompassed in the SDT motivational continuum.

\section{Procedures}

\section{Data collection}

For the study data collection, authorizations were obtained from the school direction board. All participants enrolled voluntarily and provided an informed consent signed by them and their legal guardian. Confidentiality was guaranteed and ensured. Before a PE class, a brief explanation of the study purposes was made and confortable conditions were provided to the completion of the questionnaire. The University Scientific Board approved this study with the number 1/2014-2015.

\section{Procedures of translation of the PLOCQp}

For the translation and adaptation of the $\mathrm{PLOCQ}^{12}$ from the original language (English) to Portuguese, several methodological procedures were adopted ${ }^{18,19}$. Despite using the translation/ back translation technique, we employed the committee approach methodology ${ }^{20}$. This process was developed according to the following steps: 1) Preliminary Translation; 2) First Committee; 3) Second Committee (this stage was over only when all the specialists agreed with each other and their opinion was unanimous towards the item contents); 4) Pilot Study; 5) Final Review (only syntax aspects).

\section{Data analysis}

Descriptive statistics including means and standard deviations, for the two samples were calculated for all variables. To undertake the confirmatory factor analysis, the recommendations of Byrne ${ }^{21,22,23}$ regarding the use of the estimated method of maximum likelihood (ML), chi-squared $\left(\chi^{2}\right)$ testing of the respective degrees of freedom $(\mathrm{df})$, and the level of significance (p) were used. Also, the following adjustment goodness-of-fit indexes were used: Standardized Root Mean Square Residual (SRMR), Comparative Fit Index (CFI), Non-Normed Fit Index (NNFI), Root Mean Square Error of Approximation (RMSEA) and the respective confidence interval $(90 \% \mathrm{CI})$. Traditionally, NNFI and CFI values $\geq .90$ and RMSEA and SRMR $\leq .08$ have been used as cut-off criteria. Additionally, the convergent validity was analyzed (to check if the items were related to the respective factor) via the calculation of the average variance extracted (AVE), considering values of AVE $\geq .50^{22}$ and the composite reliability (CR) was analyzed to assess the internal consistency of the factors, adopting $\mathrm{CR} \geq .70$ as the cut-off values, as suggested by Hair, Black, Babin, Anderson ${ }^{22}$. To examine if there was a distinction between factors (i.e. discriminant validity), the relation of the values of the square of the correlation between the factors was used; variance extracted estimates should be greater than the squared correlation estimate. To check the assumptions of the nomological validity of the PLOCQ, Pearson correlational analyses were used between the PLOCQ and the different types of motivation underlying SDT framework ${ }^{5}$ : amotivation, external regulation, introjected regulation, identified regulation, and intrinsic motivation. The analyses were undertaken using AMOS and SPSS 20.0. 


\section{Multi-group analysis}

A multi-group analysis is one of the crucial aspects in the development and use of psychometric instruments ${ }^{24,25}$, because it demonstrates if the measurement model structure is equivalent (invariant) across different groups with different characteristics (in the present study, across samples and gender). According to several authors ${ }^{21,24}$, invariance exists when two criteria are verified: the measurement model is adjusted to each group and to perform a multi-group analysis, considering the following invariance types: configural invariance (model without constraints), metric invariance (equality of factorial weights), scalar invariance (factorial weights and covariance equals) and residual invariance (factorial weights, covariance and equal measure errors) were assessed. Differences in values between the models without constrains (free parameters) vs. models with constrains (fixed parameters) should be verified through the difference in the $\Delta \chi^{2}$ test or by the differences in $\Delta \mathrm{CFI} \leq .01^{24}$.

\section{Nomological validity}

To analyze if constructs in a same theory framework make sense, a correlational analysis was made between the PLOCQ factors and another SDT based instrument - Engagement Scale (translated and validated by others; in preparation). This scale has four factors and 14 items: the Behavioral Engagement factor is composed by three items, and reflects how students engage in tasks in organizational settings ${ }^{26}$; the Agentic engagement is assessed by four items that tap into the students self-motivational supportive learning ${ }^{27}$; the Cognitive Engagement has three items based in achievement goal theory ${ }^{28}$ that reflect students orientations in exercise practice; the Emotional Engagement has four items to assess emotional and affective dynamics in social tasks ${ }^{26}$.

\section{Results}

\section{Preliminary Analysis}

A primary analysis of the data revealed that there were 10 multivariate outliers (i.e. six in the calibration sample; four in the validation sample) $(\mathrm{D} 2=\mathrm{p} 1<0.01 ; \mathrm{p} 2<0.01)$. These participants were removed prior to conducting any further analysis, as postulated by several authors ${ }^{21,22}$. Additionally, Mardia's coefficient for multivariate kurtosis in all samples was higher than five $($ calibration sample $=46.56$; validation sample $=77.25$ ), exceeding expected values for the assumption of multivariate normality ${ }^{21}$. Therefore, Bollen-Stine bootstrap with 2000 samples was employed for subsequent analysis ${ }^{29}$.

Descriptive analyses in Table 1 tend to show a normal univariate distribution of the data in both samples, with a slight bias to the right, and the tendency of answering near the center of the bi-polar Likert scale (i.e., three and four in a seven point scale).

Table 1 Descriptive analysis of the answers to the items on the PLOCQ in the calibration and validation samples

\begin{tabular}{|c|c|c|c|c|c|c|c|c|c|c|c|}
\hline & & $\begin{array}{c}\text { Calibra- } \\
\text { tion }\end{array}$ & Validation & $\begin{array}{c}\text { Calibra- } \\
\text { tion }\end{array}$ & Validation & $\begin{array}{c}\text { Calibra- } \\
\text { tion }\end{array}$ & Validation & $\begin{array}{c}\text { Calibra- } \\
\text { tion }\end{array}$ & Validation & $\begin{array}{c}\text { Calibra- } \\
\text { tion }\end{array}$ & Validation \\
\hline Item & $\begin{array}{l}\text { Min- } \\
\text { Max }\end{array}$ & \multicolumn{2}{|c|}{$\mathbf{M} \pm \mathbf{S D}$} & \multicolumn{2}{|c|}{ Skewness } & \multicolumn{2}{|c|}{$z$ value } & \multicolumn{2}{|c|}{ Kurtosis } & \multicolumn{2}{|c|}{$z$ value } \\
\hline $\begin{array}{l}\text { Item } 1 \\
(\mathrm{ER})\end{array}$ & $1-7$ & $3.39 \pm 2.28$ & $3.46 \pm 2.30$ & .399 & .350 & 4.360 & 3.653 & -1.319 & -1.375 & -7.120 & -7.184 \\
\hline $\begin{array}{l}\text { Item } 2 \\
\text { (IJ) }\end{array}$ & $1-7$ & $3.26 \pm 2.10$ & $3.43 \pm 2.08$ & .476 & .335 & 5.137 & 3.504 & -1.077 & -1.220 & -5.814 & -6.376 \\
\hline $\begin{array}{l}\text { Item } 3 \\
\text { (ID) }\end{array}$ & $1-7$ & $4.78 \pm 1.80$ & $4.84 \pm 1.77$ & -.499 & -.435 & -5.389 & -4.540 & -.653 & -.758 & -3.523 & -3.962 \\
\hline $\begin{array}{l}\text { Item } 4 \\
\text { (IM) }\end{array}$ & $1-7$ & $4.85 \pm 1.77$ & $4.97 \pm 1.68$ & -.486 & -.596 & -5.241 & -6.226 & -.662 & -.434 & -3.570 & -2.268 \\
\hline $\begin{array}{l}\text { Item } 5 \\
\text { (AM) }\end{array}$ & $1-7$ & $2.16 \pm 1.89$ & $1.99 \pm 1.77$ & 1.495 & 1.783 & 16.137 & 18.631 & .920 & 1.967 & 4.226 & 10.277 \\
\hline $\begin{array}{l}\text { Item } 6 \\
\text { (ER) }\end{array}$ & $1-7$ & $4.31 \pm 2.07$ & $4.16 \pm 2.13$ & -.247 & -.094 & -2.666 & -.981 & -1.168 & -1.282 & -6.304 & -6.696 \\
\hline $\begin{array}{l}\text { Item } 7 \\
\text { (IJ) }\end{array}$ & $1-7$ & $2.94 \pm 2.07$ & $2.91 \pm 2.10$ & .708 & .756 & 7.645 & 7.899 & -.862 & -.822 & -4.650 & -4.292 \\
\hline $\begin{array}{l}\text { Item } 8 \\
\text { (ID) }\end{array}$ & $1-7$ & $4.89 \pm 1.82$ & $5.14 \pm 1.72$ & -.555 & -.692 & -5.993 & -7.229 & -.657 & -.401 & -3.545 & -2.096 \\
\hline
\end{tabular}




\begin{tabular}{|c|c|c|c|c|c|c|c|c|c|c|c|}
\hline $\begin{array}{l}\text { Item } 9 \\
\text { (IM) }\end{array}$ & $1-7$ & $4.78 \pm 1.90$ & $4.83 \pm 1.91$ & -.457 & -.516 & -4.935 & -5.390 & -.862 & -.832 & -4.652 & -4.347 \\
\hline $\begin{array}{l}\text { Item } \\
10 \\
(\mathrm{AM})\end{array}$ & $1-7$ & $2.32 \pm 1.94$ & $2.12 \pm 1.74$ & 1.330 & 1.484 & 14.350 & 15.501 & .432 & 1.097 & 2.331 & 5.732 \\
\hline $\begin{array}{l}\text { Item } \\
11 \\
(E R)\end{array}$ & $1-7$ & $2.68 \pm 1.99$ & $2.53 \pm 1.94$ & .908 & 1.069 & 9.797 & 11.168 & -.480 & -.095 & -2.591 & -.497 \\
\hline $\begin{array}{l}\text { Item } \\
12(\mathrm{IJ})\end{array}$ & $1-7$ & $3.50 \pm 2.12$ & $3.37 \pm 2.20$ & .292 & .372 & 3.154 & 3.891 & -1.261 & -1.296 & -6.804 & -6.770 \\
\hline $\begin{array}{l}\text { Item } \\
13 \\
\text { (ID) }\end{array}$ & $1-7$ & $4.87 \pm 1.88$ & $4.95 \pm 1.84$ & -.600 & -.704 & -6.471 & -7.355 & -.708 & -.474 & -3.821 & -2.096 \\
\hline $\begin{array}{l}\text { Item } \\
14 \\
\text { (IM) }\end{array}$ & $1-7$ & $4.26 \pm 1.87$ & $4.48 \pm 1.80$ & -.190 & -.304 & -2.046 & -3.179 & -.914 & -.813 & -4.935 & -4.247 \\
\hline $\begin{array}{l}\text { Item } \\
15 \\
(\mathrm{AM})\end{array}$ & $1-7$ & $2.22 \pm 1.83$ & $2.10 \pm 1.71$ & 1.425 & 1.525 & 15.377 & 15.936 & .783 & 1.267 & 4.226 & 6.617 \\
\hline $\begin{array}{l}\text { Item } \\
16 \\
\text { (ER) }\end{array}$ & $1-7$ & $3.86 \pm 2.35$ & $3.64 \pm 2.25$ & .096 & .227 & 1.037 & 2.371 & -1.527 & -1.383 & -8.240 & -7.227 \\
\hline $\begin{array}{l}\text { Item } \\
17 \text { (IJ) }\end{array}$ & $1-7$ & $3.28 \pm 1.98$ & $3.20 \pm 2.00$ & .392 & .445 & 4.234 & 4.653 & -1.063 & -1.035 & -5.738 & -5.409 \\
\hline $\begin{array}{l}\text { Item } \\
18 \\
\text { (ID) }\end{array}$ & $1-7$ & $4.35 \pm 2.06$ & $4.51 \pm 1.88$ & -.254 & -.327 & -2.738 & -3.414 & -1.193 & -.905 & -6.436 & -4.730 \\
\hline $\begin{array}{l}\text { Item } \\
19 \\
\text { (IM) }\end{array}$ & $1-7$ & $4.49 \pm 1.97$ & $4.47 \pm 1.91$ & -.256 & -.269 & -2.759 & -2.813 & -1.105 & -1.038 & -5.965 & -5.421 \\
\hline $\begin{array}{l}\text { Item } \\
20 \\
(\mathrm{AM})\end{array}$ & $1-7$ & $2.22 \pm 1.84$ & $2.03 \pm 1.69$ & 1.444 & 1.662 & 15.589 & 17.365 & .881 & 1.700 & 4.755 & 8.882 \\
\hline
\end{tabular}

Note. AM (Amotivation); EX (External Regulation); IJ (Introjected regulation); ID (Identified regulation); IM (intrinsic motivation); M (Mean); SD (Standard deviation)

In Table 2, it is possible to see that the initial model (i.e., five factor and 20 items) did not have a good adjustment to the data. An analysis of the residual values between items and the modification indexes, allowed the identification of some fragilities. The model was readjusted with the elimination of two items (see final models in table 2; see figure 1), and reflected an improvement in the adjustment indexes, being in line with the values adopted in the methodology for each of the analyzed samples (i.e. calibration, validation and gender).

Table 2 Fit indices of the measurement models of PLOCQp (including existing versions)

\begin{tabular}{lcccccccc}
\hline \multicolumn{1}{c}{ Models } & $\chi^{2}$ & $\mathbf{d f}$ & $\mathbf{p}$ & SRMR & NNFI & CFI & RMSEA & 90\% CI \\
\hline PLOCQ $^{1}$ & $971.83 *$ & 320 & - & .090 & .950 & .960 & .080 & $.070-.080$ \\
Initial Model Calibration & 915.351 & 160 & $<.001$ & .067 & .861 & .883 & .082 & $.951-1.224$ \\
Final Model Calibration & 542.004 & 125 & $<.001$ & .061 & .908 & .925 & .069 & $.063-.075$ \\
Final Model Validation & 491.473 & 125 & $<.001$ & .062 & .908 & .924 & .067 & $.061-.073$ \\
Male Model & 449.601 & 125 & $<.001$ & .051 & .917 & .933 & .063 & $.405-.604$
\end{tabular}


ote. $\chi^{2}=$ chi-squared; $*$ values reported by the authors concerning the Satorra-Bentler correction of $\chi^{2}\left(\mathrm{~S}-\mathrm{B} \chi^{2}\right) ; \mathrm{df}=\mathrm{degrees}$ of freedom; SRMR $=\mathrm{Standardized}$ Root Mean Square Residual; NNFI = Non-Normed Fit Index; CFI = Comparative Fit Index; RMSEA = Root Mean Squared Error of Approximation; 90\% CI = confidence interval of RMSEA; Final Model - five factors and 18 items; ${ }^{1}$ Lonsdale, Sabiston, Taylor, Ntoumanis ${ }^{12}$; ${ }^{2}$ in preparation by others

In the model depicted in figure 1 , ordered relations between correlated variables appear, reflecting the simplex structure which is characteristic of the SDT framework ${ }^{14}$, meaning that behavioral regulations closer to each other are positively correlated, and regulations further away in the continuum have weaker or negative correlations.

Factorial weights in each factor presented statistical differences after model adjustment (all $\mathrm{p}<.05)$, indicating factorial validity. In the calibration sample, factorial weights varied between .66 and
.88 for Intrinsic Motivation, .68 and .82 for Identified Regulation, .68 and .80 for Introjected Regulation, .59 and .65 for External Regulation and .51 and .77 for Amotivation. In the validation sample, values ranged between .61 and .83 for Intrinsic Motivation, .69 and .81 for Identified Regulation, .69 and .79 for Introjected Regulation, .50 and .67 for External regulation and .43 and .80 for Amotivation. Except for item 16 (validation sample), all the other items explained more than $25 \%$ of the variance of the latent factor $\left(\lambda \mathrm{ij}^{2} \geq .25\right)$, as recommended by Hair, Black, Babin, Anderson ${ }^{22}$.

Figure 1 Standardized individual parameters (covariance factors, factorial weights and measurement errors), all of which were significant in the measurement model (PLOCQp - Five factors/18 items) for the Portuguese calibration sample

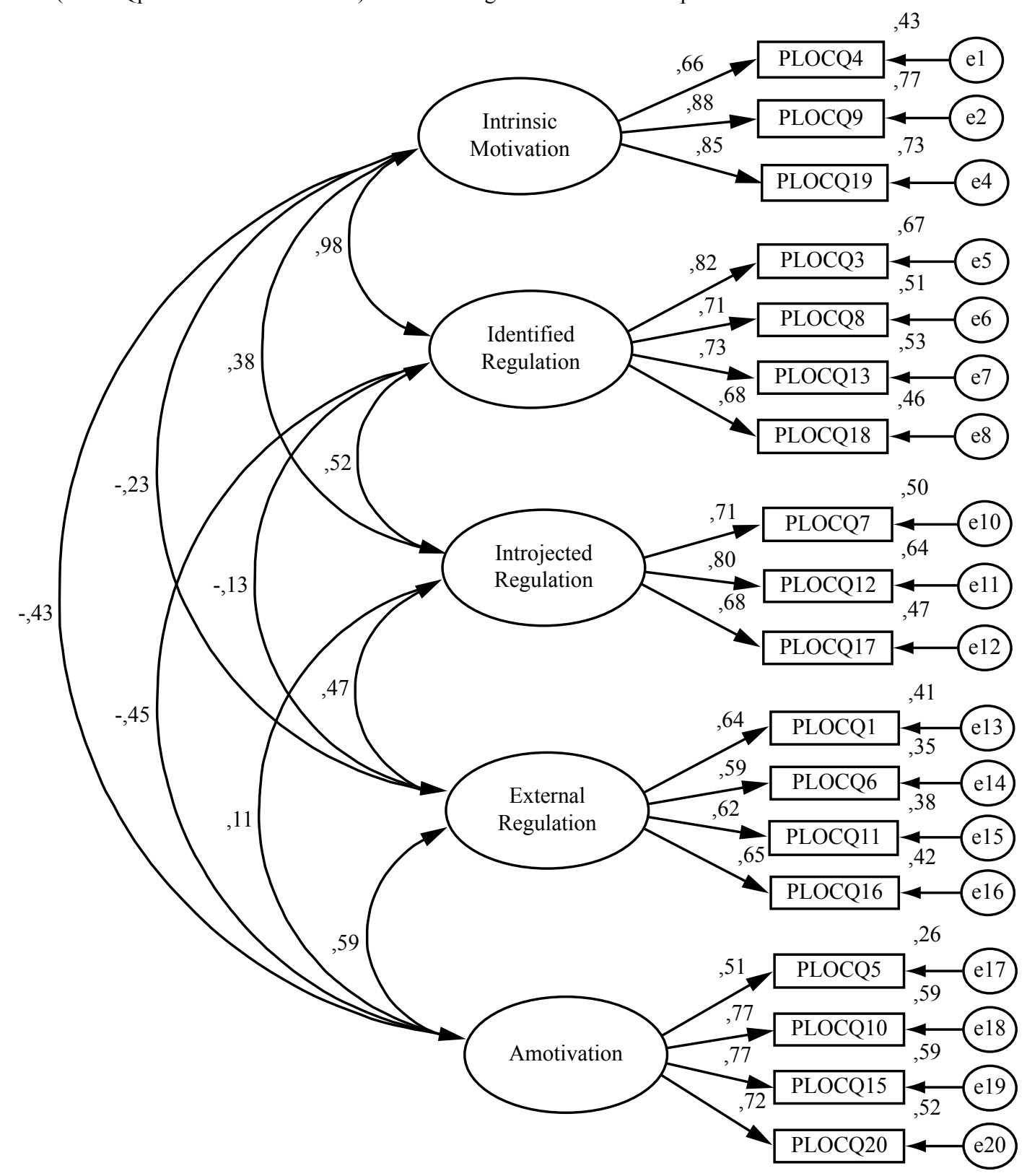


Figure 2 Standardized individual parameters (covariance factors, factorial weights and measurement errors), all of which were significant in the measurement model (PLOCQp - Five factors/18 items) for the Portuguese validation sample

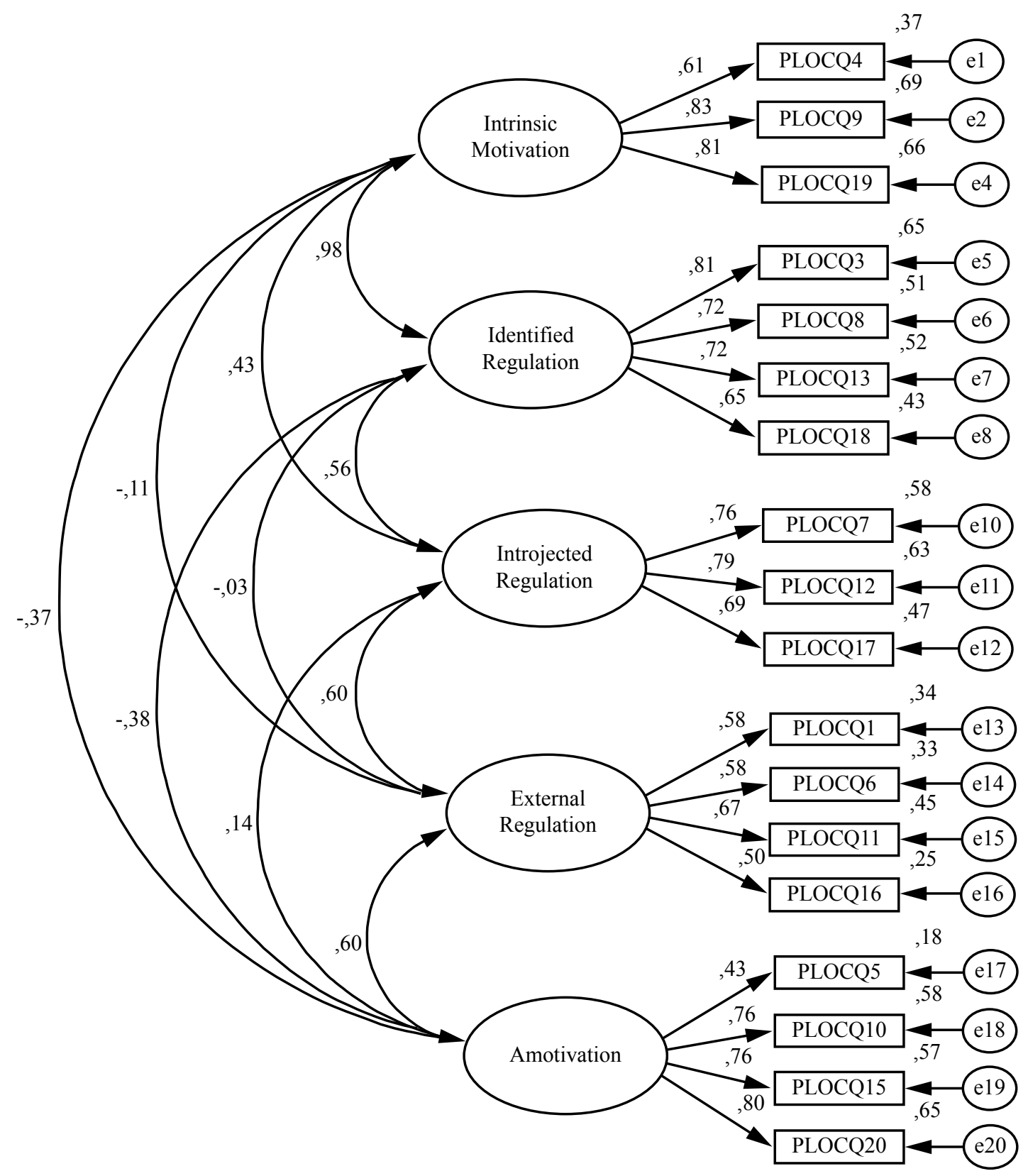

Results in table 3 show that most factors in the measurement model presented an adjusted composite reliability $(\geq .70)$. The only exception was for external regulation in the validation sample, where $\mathrm{CR}=.67$ is considered acceptable when other indicators of construct validity are good (Hair, Black, Babin, Anderson ${ }^{22}$ ). Concerning convergent validity, the AVE was calculated and presented minor issues in both samples, as some values were under the adopted in methodology (CS amotivation and external regulation $<.50$; VS external regulation $<.50)^{22}$. In the discriminant validity analysis, some issues were detected in intrinsic motivation-identified regulation for the calibration sample and external regulation-amotivation and intrinsic motivation-identified regulation in the validation sample, where the square of the factor's correlations between factors were higher than the AVE ${ }^{22}$.

Table 3 Internal reliability, convergent and discriminant validity and average variance extracted - Calibration and Validation samples

\begin{tabular}{lccccccc}
\hline Factors (calibration) & CR & AVE & AM & ER & IJ & ID & IM \\
\hline AM & .79 & .49 & 1 & - & - & - & -
\end{tabular}




\begin{tabular}{|c|c|c|c|c|c|c|c|}
\hline ER & .72 & .39 & $.34 *$ & 1 & - & - & - \\
\hline IJ & .78 & .54 & $.01 *$ & $.22 *$ & 1 & - & - \\
\hline ID & .83 & .54 & $.20 *$ & $.02 *$ & $.27 *$ & 1 & - \\
\hline $\mathrm{IM}$ & .84 & .64 & $.18^{*}$ & $.05^{*}$ & $.14^{*}$ & $.97 *$ & 1 \\
\hline Factors (validation) & $\mathrm{CR}$ & AVE & $\mathrm{AM}$ & ER & $\mathrm{IJ}$ & ID & IT \\
\hline $\mathrm{AM}$ & .79 & .50 & 1 & - & - & - & - \\
\hline ER & .67 & .34 & $.36^{*}$ & 1 & - & - & - \\
\hline IJ & .73 & .56 & $.02 *$ & $.36^{*}$ & 1 & - & - \\
\hline ID & .82 & .53 & $.15^{*}$ & $<.001 *$ & .31 & 1 & - \\
\hline $\mathrm{IM}$ & .70 & .57 & $.13^{*}$ & $.13^{*}$ & $.19^{*}$ & $.97 *$ & 1 \\
\hline
\end{tabular}

Note. Composite Reliability (CR); Average Variance Extracted (AVE); AM= amotivation; EX: external regulation; IJ: introjected regulation; ID= identified regulation; IM= intrinsic motivation; * (r2).

According to the results in table 2, all samples presented a good adjustment (i.e., calibration, validation, male and female samples). The invariance analysis of these models is expressed in table 5 , where results point to invariant models between samples (i.e., cross validation across calibration and validation samples; invariance across genders). These results suggest the following: in the configural invariance, the same number of factors was present in each group, remaining associated with the same group of items; in metric invariance, the factors of PLOCQp had the same understanding for both groups; in scale invariance, the latent and observable means were compared and valid among groups; in residual invariance, comparison between observable items was supported.

Finally, nomological validity procedures showed a clear and SDT-coherent relation between PLOCQp and EEp. The autonomous types of motivation were positively related with all forms of student's engagement, and the controlled types presented weaker or negative associations with engagement.

Table 4 Fit indices for the invariance of the measurement model of the PLOCQ in the Portuguese sample across samples and gender

\begin{tabular}{|c|c|c|c|c|c|c|c|}
\hline & $\chi^{2}$ & df & $\Delta \chi^{2}$ & $\Delta \mathbf{d f}$ & $\mathrm{p}$ & CFI & $\Delta \mathbf{C F I}$ \\
\hline \multicolumn{8}{|l|}{ CS - VS } \\
\hline Configural Invariance & 1033.476 & 250 & - & - & - & .925 & - \\
\hline Measurement Invariance & 1052.619 & 263 & 19.144 & 13 & .119 & .924 & .001 \\
\hline Scale Invariance & 1063.991 & 278 & 30.515 & 28 & .339 & .925 & .000 \\
\hline Residual Invariance & 1113.033 & 296 & 79.557 & 46 & .002 & .922 & .003 \\
\hline \multicolumn{8}{|l|}{ M - F } \\
\hline Configural Invariance & 1009.917 & 250 & - & - & - & .927 & \\
\hline Measurement Invariance & 1038.488 & 263 & 28.571 & 13 & .008 & .925 & .002 \\
\hline Scale Invariance & 1060.637 & 278 & 50.720 & 28 & .005 & .924 & .003 \\
\hline Residual Invariance & 1082.785 & 296 & 72.868 & 46 & .007 & .924 & .003 \\
\hline
\end{tabular}

Note. $\chi^{2}=$ chi-squared; $\mathrm{df}=$ degrees of freedom; $\Delta \chi^{2}=$ differences in the value of chi-squared; $\Delta d f=$ differences in the degrees of freedom; CFI $=$ Comparative Fit Index; $\Delta \mathrm{CFI}=$ differences in the value of the Comparative Fit Index

Table 5 Nomological validity

\begin{tabular}{cccccc}
\hline \multicolumn{1}{c}{ Variables } & Intrinsic & Identified & Introjected & External & Amotivation \\
\hline Behavioral Engagement & $.688^{* *}$ & $.703 * *$ & $.356^{* *}$ & -.133 & $-.372^{* *}$ \\
Agentic Engagement & $.635^{* *}$ & $.628^{* *}$ & $.311^{* *}$ & $-.088^{*}$ & $-.217^{* *}$
\end{tabular}




\begin{tabular}{llllll} 
Cognitive Engagement & $.780^{* *}$ & $.806^{* *}$ & $.406^{* *}$ & $-.134 * *$ & $-.294 * *$ \\
Emotional Engagement & $.901 * *$ & $.813^{* *}$ & $.331^{* *}$ & $-.232 * *$ & $-.509 * *$ \\
\hline
\end{tabular}

Note. $* \mathrm{p}<.05,{ }^{* *} \mathrm{p}<.01$

\section{Discussion}

The purpose of this study was to translate and validate the Perceived Locus of Causality Questionnaire (PLOCQ) to the Portuguese context. Psychometric properties and invariance across samples (i.e., cross-validation) and gender were examined to ensure proper instrument feasibility and to provide to PE professionals an instrument capable of assessing the motivational continuum in students, contributing also towards what Deci and Ryan ${ }^{30}$ called the development of knowledge regarding the universality of underlying variables of SDT which, in this specific case, is related with the behavioral regulation within a PE context.

Psychometric analysis of the Portuguese version of the PLOCQ showed that the initial hypothesized model (five factors / 20 items) did not fit the pre-defined values adopted in methodology $y^{21,22,23}$. For this matter, individual parameters were analyzed, and two items (intrinsic motivation-14; introjected regulation -2) were removed because they showed associations with other factors (e.g., the item 2, "Because I want the PE teacher to think I am a good student" presented an association with external regulation). This may suggest that proximity in motivational continuum reflects some difficulty in interpreting what was supposed in students with this particular question. Some authors have also suggested that, when analyzing the motivational continuum in exercise settings, a bivalent introjected regulation may, in some individuals, reflect a more positive or negative valence ${ }^{31.32}$ that may justify these interpretations. After these items removal, the final model (i.e., five factors / 18 questions) presented good adjustment values in all samples and was in line with the pre-defined methodology requirements.

Further analysis also revealed good psychometric properties. According to Hair, Black, Babin, Anderson ${ }^{22}$, construct validity is defined as the extent to which the research is accurate. The internal consistency (i.e., composite reliability) of the factors was adequate, according to the criteria adopted as part of the methodology, although one factor (external regulation in the validation sample) had a value of less than .70 , but always greater than .60, which can be considered an acceptable limit'22, especially when dealing with factors with few items. Besides that, in the study of Lonsdale, Sabiston, Taylor, Ntoumanis ${ }^{12}$, specifically in the Hong Kong sample, the authors also found a similar value of composite reliability.

Regarding convergent validity, some issues can be verified within the factors amotivation and external regulation (calibration sample) and external regulation (validation sample), because the AVE values were lower than the ones adopted as part of the methodology ( $\geq .50)$, that is, the items were not strongly associated with these factors, although, the factorial weights were greater than .50 and statistically significant within the respective factors. According to Hair, Black, Babin, Anderson ${ }^{22}$, this is an indicator of suitable convergent validity. Also, neither of these items showed cross-loadings nor very high residual values, being an adjustment indicator of the items on those factors ${ }^{21}$.

On the other hand, some factors showed issues, namely identified regulation-intrinsic motivation and amotivationexternal regulation (both samples), that is, the factors were not distinguishable enough from each other ${ }^{22}$. Similar results were reported in the original version of this questionnaire developed by Lonsdale, Sabiston, Taylor, Ntoumanis ${ }^{12}$ and other studies in the physical education domain. Still, in the sports domain, similar results were found, both in the Behavioral Regulation Sports Questionnaire version $\left(\mathrm{BRSQ}^{33}\right)$ and in the two versions of Sports Motivation Scale $\left(\mathrm{SMS}^{34,35}\right)$. This seems to indicate that there is not a universal support for the discriminant validity involving these constructs. However, Ryan and Connell ${ }^{14}$ justify the high correlation patterns because the behavioral regulations are presented in a continuum of motivation where contiguous regulations are theoretically close and positively associated, which seems to be the justification for the lack of discriminant validity involving amotivation and external regulation, as well as, identified and intrinsic motivation. Deci and Ryan $^{3,30}$ highlight this issue, emphasizing that the SDT constructs underlying the autonomous and controlled motivation types correlate highly among themselves. Several studies in different contexts have reported the same results: exercise $\mathrm{e}^{36,37}$ and Sport ${ }^{33,34,35}$.

For the invariance analysis (i.e., across samples and gender) the suggested recommendations from several authors were followed (e.g., Byrne ${ }^{21}$ ). The re-specification of the model implies that when a model does not present adjustment to the data, the final (re-specified) model should be tested in another sample of the same population, ensuring proper validity and robustness. Therefore, the final model, primarily defined and tested in the calibration sample, was once again tested on the validation sample, presenting an adjustment to the data and in line with the values adopted previously ${ }^{21,23}$. In both cross-validation and gender invariance, all criteria were met, showing that the theoretical constructs underlying the measurement model were perceived in the same way by both genders, allowing comparisons between male and female PE students ${ }^{25}$.

Thus, considering the assumptions from operationalized multi-group analysis in the methodology $y^{21,24}$, it is possible to affirm the following to both samples and gender: i) configural invariance is verified as the same items group that explains the same factors group is maintained, independently of sample and gender; ii) the factorial weight of the items is equivalent for both samples and gender (measurement invariance), in other words, the items have the same importance regardless of the group; iii) the item intercepts are invariant (equivalents) in both samples and gender, consequently representing scale invariance (i.e., strong invariance). This type of invariance is the most important, because when this assumption is verified, it 
means it is legitimate to make results comparisons in different groups, in this case across samples and genders, based on the behavioral regulation, underlying $\mathrm{SDT}^{40}$; iv) residual invariance was verified, because the factorial weights, covariance and error of measurement model operate the same way across samples and genders ${ }^{21,24}$. Thus, these results support PLOCQp use in PE context, as the model presented cross-validation criteria and reveled to be gender invariant, supporting that the theoretical construct underlying the measurement model is interpreted in the same way between male and female students.

Despite addressing a gap in the literature regarding motivational regulations measurement in the present context, some limitations are evident: i) the validated version do not encompass all of the SDT behavioral regulations (i.e., integrated regulation). Thus, we suggest that future endeavors should try to address this issue for the PE context; ii) in addition to cross-validation, future studies should focus in longitudinal invariance analysis (e.g., throughout the school year) in order to increase the robustness of the instrument; iii) analyze invariance across different age groups (e.g., middle school and high school), to understand if the instrument is interpreted in the same way despite age differences.

Therefore, and despite study limitations, the present work provides an instrument that allows behavioral regulation in Portuguese and PE settings, providing teachers a specialized tool to help them better understand student behavior in class. This may be important in order to prevent some unwanted behaviors, low in-class task adherence, or feelings of boredom, simultaneous helping teacher to plan more engaging and joyful classes, acting as promoters of intrinsic motivation. This issue is particularly important as intrinsic motivation is among the most highlighted factors to the maintenance of behavior over time ${ }^{41}$.

In short, this study suggests that PLOCQp with five factors and 18 items has good psychometric properties and can be used to assess contextual motivation towards PE in the Portuguese context. Invariance analysis shows support for the use of the instrument in both genders.

\section{References}

1. Hagger M, Chatzisarantis L. The Trans-Contextual Model of Autonomous Motivation in Education: Conceptual and Empirical Issues and Meta-Analysis. Review of Educational Research. 2015; 20, 1-48. doi: 10.3102/0034654315585005

2. Deci E, Ryan R. Intrinsic Motivation and Self-Determination in Human Behavior. New York: Plenum Press, 1985.

3. Ryan R, Deci E. Self-determination theory and the facilitation of intrinsic motivation, social development, and wellbeing. The American Psychologist. 2000; 55(1), 68-78. doi:10.1037/0003-066X.55.1.68

4. Sebire SJ, Standage M. Vansteenkiste M. Examining intrinsic versus extrinsic exercise goals: Cognitive, affective, and behavioral outcomes. Journal of Sport \& Exercise Psychology. 2009; 31(2), 189-210. doi:10.1123/jsep.31.2.189

5. Deci E, Ryan R. The "What" and "Why" of Goal Pursuits: Human Needs and the Self-Determination of Behavior. Psychological Inquiry. 2000; 11(4), 227-268. doi: 10.1207/ S15327965PLI1104_01
6. Teixeira P, Carraça E, Markland D, Silva M, Ryan R. Exercise, physical activity, and self-determination theory: A systematic review. International Journal of Behavioral Nutrition and Physical Activity. 2012; 9, 78. doi:10.1186/1479-5868-9-78

7. Standage M, Duda JL, Ntoumanis N. A test of self-determination theory in school physical education. British Journal of Educational Psychology. 2005; 75, 411-433. doi: 10.1348/000709904X22359

8. Standage M, Duda JL. Ntoumanis N. A model of contextual motivation in physical education: Using constructs from selfdetermination and achievement goal theories to predict physical activity intentions. Journal of Educational Psychology. 2003; 95, 97-110. doi:10.1037/0022-0663.95.1.97

9. Teixeira DS, Palmeira AL. Analysis of the indirect effects of the quality of motivation on the relation between need satisfaction and emotional response to exercise. International Journal of Sport Psychology. 2015; 46, 295-310. doi: 10.7352/IJSP 2015.46.295

10. Ryan R, Deci E. Self-Determination Theory. Basic Psychological Needs in Motivation, Development and Wellness. New York: The Guilford Press, 2017.

11. Ntoumanis N, Standage M. Motivation in physical education classes: a self-determination theory perspective. Journal of Research and Theory in Education. 2009; 7, 194-202. doi: $10.1177 / 1477878509104324$

12. Lonsdale C, Sabiston C, Taylor I, Ntoumanis N. Measuring student motivation for physical education: Examining the psychometric properties of the Perceived Locus of Causality Questionnaire and the Situational Motivation Scale. Psychology of Sport and Exercise. 2010; 12, 284-292. doi: 10.1016/j.psychsport.2010.11.003

13. Goudas M, Biddle S, Fox K. Perceived locus of causality, goal orientations, and perceived competence in school physical education classes. British Journal of Educational Psychology. 1994; 64, 453-463. doi: 10.1111/j.2044-8279.1994.tb01116.x

14. Ryan R, Connell J. Perceived Locus of Causality and Internalization: Examining Reasons for Acting in Two Domains. Journal of Personality and Social Psychology. 1989; 57, 749-761. doi: 10.1037/0022-3514.57.5.749

15. Vallerand R, Pelletier L, Blais M, Brière N, Senécal C, Vallières $\mathrm{E}$. The academic motivation scale: A measure of intrinsic, extrinsic, and amotivation in education. Education and Psychological Measurement. 1992; 52, 1003-1017. doi: $10.1177 / 0013164492052004025$

16. Ntoumanis N. A prospective study of participation in optional school psysical education using a self-determination theory framework. Journal of Educational Psychology. 2005; 97, 444-453. doi:10.1037/0022-0663.97.3.444

17. Taylor IM, Ntoumanis N. Teacher motivational strategies and student self-determination in physical education. Journal of Educational Psychology. 2007; 99, 747-760.doi: 10.1037/0022-0663.99.4.747

18. Vallerand R. Vers une méthodologie de validation transculturelle de questionnaires psychologiques: Implications pour la recherche en langue française. Canadian Psychology. 1989, 30, 662-680. doi: 10.1037/h0079856

19. Banville D, Desrosiers P, Genet-Volet Y. Translating Questionnaires and Inventories Using a Cross-Cultural Translation Technique. Journal of Teaching in Physical Education. 2000; 19, 374-387. doi: 10.1123/jtpe.19.3.374

20. Brislin R. Translation and content analysis for oral and written material. In H. Triandis \& J. Berry (Eds.), Handbook of CrossCultural Psychology (Vol. 2, pp. 389-444). Needham Heights, MA: Allyn and Bacon, 1980. 
21. Byrne B. Structural equation modelling with AMOS. Basic concepts, applications, and programming ( $2^{\text {nd }} \mathrm{ed}$.) Madison, Avenue, New York: Taylor \& Francis Group, LLC, 2010.

22. Hair J, Black W, Babin B, Anderson, R. Multivariate Data Analysis (7th ed.). New Jersey: Pearson Educational, Inc., 2014.

23. Marsh H, Hau K, Wen Z. In search of golden rules: Comment on hypothesis-testing approaches to setting cutoff values for fit indexes and dangers in overgeneralizing Hu and Bentler's (1999) findings. Structural Equation Modeling. 2004; 11(3), 320-341. doi: 10.1207/s15328007sem1103_2

24. Cheung G, Rensvold R. Evaluating goodness-of-fit indexes for testing measurement invariance. Structural Equation Modelling: A Multidisciplinary Journal. 2002; 9, 233-255. doi:10.1207/ S15328007SEM0902_5

25. Sass D. Testing measurement invariance and comparing latent factor means within a confirmatory factor analysis framework. Journal of Psychoeducational Assessment. 2011; 29, 347-363. doi: 10.1177/0734282911406661

26. Skinner EA, Kindermann TA, Connell JP, Wellborn JG. Engagement and disaffection as organizational constructs in the dynamics of motivational development. In K. Wentzel \& A. Wigfield (Eds.), Handbook of motivation in school (pp. 223-245). Mahwah, NJ: Erlbaum, 2009.

27. Reeve J. How Students Create Motivationally Supportive Learning Environments for Themselves: The Concept of Agentic Engagement. Journal of Educational Psychology. 2013; 105, 579-595. doi:10.1037/a0032690

28. Nicholls J. Achievement Motivation: Conceptions of Ability, Subjective Experience, Task Choice, and Performance. Psychological Review. 1984; 91(3), 328-346. doi: 10.1037/0033295x.91.3. 328

29. Nevitt J, Hancock GR. Performance of bootstrapping approaches to model test statistics and parameter standard error estimation in structural equation modeling. Structural Equation Modeling. 2001; 8, 353-377. http://dx.doi.org/10.1207/S15328007SEM0803_2.

30. Deci E, Ryan R. Facilitating Optimal Motivation and Psychological Well- Being Across Life's Domains. The Canadian Psychological Association. 2008; 49, 14-23.

31. Assor A, Vansteenkiste M, Kaplan A. Identified versus introjected approach and introjected avoidance motivations in school and in sports: The limited benefits of self-worth strivings. Journal of Educational Psychology. 2009; 101, 482-497.

32. Teixeira DS, Palmeira AL. Needs Satisfaction Effect on Exercise Emotional Response: A Serial Mediation Analysis with Motivational Regulations and Exercise Intensity. Motriz. 2016; 22, 1-9. doi: http://dx.doi.org/10.1590/S1980-6574201600040002

33. Lonsdale $\mathrm{C}$, Hodge $\mathrm{K}$, Rose E. The Behavioral Regulation in Sport Questionnaire (BRSQ): Instrument Development and Initial
Validity Evidence. Journal of Sport y Exercise Psychology. 2008; 30, 323-355. doi: 10.1016/j.psychsport.2014.03.006

34. Pelletier L, Fortier M, Vallerand R, Tuson M, Briére M, Blais R. Toward a new measure of intrinsic motivation, extrinsic motivation, and amotivation in sports: The sport motivation scale (SMS). Journal of Sport and Exercise Psychology. 1995; 17, 35-53. doi:10.1123/jsep.17.1.35

35. Pelletier L, Rocchi A, Vallerand R, Deci E, Ryan R. Validation of the revised sport motivation scale (SMS-II). Psychology of Sport and Exercise. 2013; 14, 329-341. doi: 10.1016/j. psychsport.2012.12.002

36. Cid L, Moutão J, Leitão J, Alves J. Behavioral regulation assessment in exercise: exploring an autonomous and controlled motivation index. Spanish Journal of Psychology. 2012; 15, 1520-8. doi: 10.5209/rev_SJOP.2012.v15.n3.39436

37. Markland D, Tobin V. A Modification to the Behavioural Regulation in Exercise Questionnaire to Include an Assessment of Amotivation, Journal of Sport and Exercise Psychology. 2004; 26, 191-196. doi.org/10.1123/jsep.26.2.191

38. Monteiro D, Moutão J, Cid, L. Validation of the Behavioral Regulation Sport Questionnaire in Portuguese Athletes. Revista de Psicologia del Desporte, 2018; 27, 145-150

39. Clancy R, Herring M, Campbell M. Motivation Measures in Sport: A Critical Review and Bibliometric Analysis. Frontiers in Psychology, 2017; 8, 1-12. doi: 10.3389/fpsyg.2017.00348

40. Chen F. What happens if we compare chopsticks with forks? The impact of making inappropriate comparisons in cross-cultural research. Journal of Personality and Social Psychology. 2008; 95, 1005-1018. doi: 10.1037/a0013193

41. Pannekoek L, Piek J, Hagger M. The Children's Perceived Locus of Causality Scale for Physical Education. Journal of Teaching in Physical Education. 2014; 33, 162-185. https://doi.org/10.1123/ jtpe.2013-0095

\section{Corresponding author}

*Diogo S. Teixeira

Universidade Lusófona de Humanidades e Tecnologias, Faculdade de Educação Física e Desporto. Lisboa, Portugal.

Email: diogo.sts.teixeira@gmail.com

Orcid: http://orcid.org/0000-0003-4587-5903

Manuscript received on December 7, 2017

Manuscript accepted on February 22, 2018

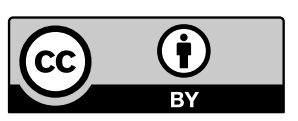

Motriz. The Journal of Physical Education. UNESP. Rio Claro, SP, Brazil - eISSN: 1980-6574 - under a license Creative Commons - Version 4.0 
In the article "Translation and validation of the perceived locus of causality questionnaire (PLOCQ) in a sample of portuguese physical education students", published in volume 24, number 2, 2018: DOI: 10.1590/S1980-6574201800020007 and identification: e1018162.

In the page 1:

\section{Where it was written}

This study suggests that PLOCQ with five factors and 18 items has good psychometric proprieties and can be used to assess contextual motivation towards PE in the Portuguese context.

\section{Should read:}

This study suggests that PLOCQ with five factors and 18 items has good psychometric properties and can be used to assess contextual motivation towards PE in the Portuguese context.

In the page 1:

\section{Where it was written}

This instrument was initially developed by Goudas, Biddle and Fox ${ }^{13}$ through an adaptation of the Self-Regulation Questionnaire developed by Ryan and Connel ${ }^{14}$.

\section{Should read:}

This instrument was initially developed by Goudas, Biddle and Fox ${ }^{13}$ through an adaptation of the Self-Regulation Questionnaire developed by Ryan and Connel1 ${ }^{14}$.

In the page 2, section Method, subsection Participants:

\section{Where it was written}

Two independent samples of PE students were used in this study to ensure the robustness of the measurement instrument in a sample of the same population.

The first set of participants consisted of 699 students and represented the calibration sample, with ages comprised between 12 and 23 years old ( $\mathrm{M}=15.49 ; \mathrm{SD}=1.93)$, and enrolled in two PE classes/week (135 min total). The validation sample was composed of 655 students, with ages between 12 and 23 years old $(M=15.47 ; S D=1.88)$, and had the same amount of $\mathrm{PE} /$ week than previous sample. The global sample comprised 652 boys $(\mathrm{M}=15.4$ years; $\mathrm{SD}=1.90)$ and 702 girls ( $\mathrm{M}=15.47$ years; $\mathrm{SD}=1.95)$. 


\section{Should read:}

Physical education students of four Lisbon public schools were invited to participate in this study. The students were enrolled in the $3^{\text {rd }}$ cycle $\left(7^{\text {th }}, 8^{\text {th }}\right.$ and $9^{\text {th }}$ grades $)$ and secondary cycle $\left(10^{\text {th }}, 11^{\text {th }}\right.$ and $12^{\text {th }}$ years $)$ Study information and permissions were sent to the schools direction board and parents. After obtaining the study permissions, the students were debriefed about the study aims and their participation previous to the questionnaires delivery. The PE teachers were informed of the requirements necessary to apply the questionnaires. A calm and peaceful environment were provided in a class room to the students before the class starts, in order to read, fill and ask any doubts regarding the questionnaires. No dropouts were reported in this stage.

Two independent samples of PE students were used in this study to ensure the robustness of the measurement instrument in a sample of the same population.

The first set of participants consisted of 699 students and represented the calibration sample, with ages comprised between 12 and 23 years old $(M=15.49 ; \mathrm{SD}=1.93)$, with 332 males and 367 females, enrolled in two PE classes/week (135 min total). The validation sample was composed of 655 students, with ages between 12 and 23 years old (M=15.47; $\mathrm{SD}=1.88), 312$ males and 343 females, with the same amount of PE/week than previous sample. The global sample comprised 644 boys $(M=15.4$ years; $S D=1.90)$ and 710 girls $(M=15.47$ years; $S D=1.95)$, were 650 students were enrolled in the 3rd cycle (ages 12 to 17 years) and 704 in secondary cycle (ages 17 to 23 years).

In the page 3:

\section{Where it was written}

A primary analysis of the data revealed that there were ${ }^{10}$ multivariate outliers (i.e. six in the calibration sample; four in the validation sample $)(\mathrm{D} 2=\mathrm{p} 1<0.01 ; \mathrm{p} 2<0.01)$. These participants were removed prior to conducting any further analysis, as postulated by several authors ${ }^{21,22}$.

\section{Should read:}

A primary analysis of the data revealed that there were ${ }^{10}$ multivariate outliers (i.e., six in the calibration sample; four in the validation sample) $(\mathrm{D} 2=\mathrm{p} 1<0.01 ; \mathrm{p} 2<0.01)$. These participants were removed prior to conducting any further analysis, as postulated by several authors ${ }^{21,22}$.

In the page 4:

\section{Where it was written}

In Table 2, it is possible to see that the initial model (i.e., five factor and 20 items) did not have a good adjustment to the data. An analysis of the residual values between items and the modiication indexes, allowed the identiication of some fragilities. The model was readjusted with the elimination of two items (see final models in table 2; see Figure 1), and relected an improvement in the adjustment indexes, being in line with the values adopted in the methodology for each of the analyzed samples (i.e. calibration, validation and gender).

\section{Should read:}

In Table 2, it is possible to see that the initial model (i.e., five factor and 20 items) did not have a good adjustment to the data. An analysis of the individual parameters based on the modification indices revealed that two items (item 14 - intrinsic motivation, and item 2 - introjected regulation), are cross-loadings. These items were therefore removed from 
the model, as suggested by several authors ${ }^{21,22}$. Following these modifications, the final model (re-specified) provided a good fit to the data for all samples under analysis.

In the page 4, Table 2:

\section{Where it was written}

Table 2 Fit indices of the measurement models of PLOCQp (including existing versions)

\begin{tabular}{lcccccccc}
\hline \multicolumn{1}{c}{ Models } & $\boldsymbol{\chi}^{\mathbf{2}}$ & $\mathbf{d f}$ & $\mathbf{p}$ & SRMR & NNFI & CFI & RMSEA & $\mathbf{9 0 \%}$ CI \\
\hline PLOCQ $^{1}$ & $971.8 *^{*}$ & 320 & - & .090 & .950 & .960 & .080 & $.070-.080$ \\
Initial Model Calibration & 915.351 & 160 & $<.001$ & .067 & .861 & .883 & .082 & $.951-1.224$ \\
Final Model Calibration & 542.004 & 125 & $<.001$ & .061 & .908 & .925 & .069 & $.063-.075$ \\
Final Model Validation & 491.473 & 125 & $<.001$ & .062 & .908 & .924 & .067 & $.061-.073$ \\
Male Model & 449.601 & 125 & $<.001$ & .051 & .917 & .933 & .063 & $.405-.604$ \\
Female Model & 560.320 & 125 & $<.001$ & .068 & .904 & .921 & .070 & $.065-.076$ \\
Engagement $^{2}$ & 7413.507 & 91 & $<.001$ & .043 & .913 & .932 & .069 & - \\
\hline
\end{tabular}

Note. $\chi^{2}=$ chi-squared; * values reported by the authors concerning the Satorra-Bentler correction of $\chi^{2}\left(\mathrm{~S}-\mathrm{B} \chi^{2}\right) ; \mathrm{df}=$ degrees of freedom; SRMR $=\mathrm{Standardized}$ Root Mean Square Residual; NNFI = Non-Normed Fit Index; CFI = Comparative Fit Index; RMSEA = Root Mean Squared Error of Approximation; 90\% CI = confidence interval of RMSEA; Final Model - five factors and 18 items; ${ }^{1}$ Lonsdale, Sabiston, Taylor, Ntoumanis ${ }^{12} ;{ }^{2}$ in preparation by others

\section{Should read:}

Table 2 Fit indices of the measurement models of PLOCQp (including existing versions)

\begin{tabular}{|c|c|c|c|c|c|c|c|c|}
\hline Models & $\chi^{2}$ & df & B-S p & SRMR & NNFI & CFI & RMSEA & $90 \% \mathrm{CI}$ \\
\hline PLOCQ $^{1}$ & $971.83^{*}$ & 320 & - & .090 & .950 & .960 & .080 & $.070-.080$ \\
\hline Initial Model Calibration & 915.351 & 160 & $<.001$ & .067 & .861 & .883 & .082 & $.951-1.224$ \\
\hline Final Model Calibration & 542.004 & 125 & $<.001$ & .061 & .908 & .925 & .069 & $.063-.075$ \\
\hline Final Model Validation & 491.473 & 125 & $<.001$ & .062 & .908 & .924 & .067 & $.061-.073$ \\
\hline Male Model & 449.601 & 125 & $<.001$ & .051 & .917 & .933 & .063 & $.405-.604$ \\
\hline Female Model & 560.320 & 125 & $<.001$ & .068 & .904 & .921 & .070 & $.065-.076$ \\
\hline 3rd cycle & 409.633 & 125 & $<.001$ & .055 & .925 & .939 & .060 & $.054-.067$ \\
\hline Secondary cycle & 625.733 & 125 & $<.001$ & .075 & .900 & .912 & .075 & $.070-.081$ \\
\hline Engagement $^{2}$ & 7413.507 & 91 & $<.001$ & .043 & .913 & .932 & .069 & - \\
\hline
\end{tabular}

Note. $\chi^{2}=$ chi-squared; * values reported by the authors concerning the Satorra-Bentler correction of $\chi^{2}\left(\mathrm{~S}-\mathrm{B} \chi^{2}\right) ; \mathrm{df}=$ degrees of freedom; SRMR $=\mathrm{Standardized}$ Root Mean Square Residual; NNFI = Non-Normed Fit Index; CFI = Comparative Fit Index; RMSEA = Root Mean Squared Error of Approximation; $90 \%$ CI = confidence interval of RMSEA; Final Model - five factors and 18 items; ${ }^{1}$ Lonsdale, Sabiston, Taylor, Ntoumanis ${ }^{12} ;{ }^{2}$ in preparation by others

In the page 7, Table 3:

\section{Where it was written}

Table 3 Internal reliability, convergent and discriminant validity and average variance extracted - Calibration and Validation samples

\begin{tabular}{|c|c|c|c|c|c|c|c|}
\hline Factors (calibration) & CR & AVE & $\mathbf{A M}$ & ER & $\mathbf{I J}$ & ID & IM \\
\hline AM & .79 & .49 & 1 & - & - & - & - \\
\hline ER & .72 & .39 & $.34^{*}$ & 1 & - & - & - \\
\hline IJ & .78 & .54 & $.01 *$ & $.22 *$ & 1 & - & - \\
\hline ID & .83 & .54 & $.20^{*}$ & $.02 *$ & $.27 *$ & 1 & - \\
\hline $\mathrm{IM}$ & .84 & .64 & $.18^{*}$ & $.05^{*}$ & $.14^{*}$ & $.97^{*}$ & 1 \\
\hline
\end{tabular}




\begin{tabular}{|c|c|c|c|c|c|c|c|}
\hline Factors (validation) & $\mathrm{CR}$ & AVE & $\mathrm{AM}$ & ER & $\mathrm{IJ}$ & ID & IT \\
\hline $\mathrm{AM}$ & .79 & .50 & 1 & - & - & - & - \\
\hline ER & .67 & .34 & $.36^{*}$ & 1 & - & - & - \\
\hline IJ & .73 & .56 & $.02 *$ & $.36^{*}$ & 1 & - & - \\
\hline ID & .82 & .53 & $.15^{*}$ & $<.001 *$ & .31 & 1 & - \\
\hline IM & .70 & .57 & $.13^{*}$ & $.13^{*}$ & $.19^{*}$ & $.97 *$ & 1 \\
\hline
\end{tabular}

Note. Composite Reliability (CR); Average Variance Extracted (AVE); AM= amotivation; EX: external regulation; IJ: introjected regulation; ID= identified regulation; IM= intrinsic motivation; * (r2).

\section{Should read:}

Table 3 Internal reliability, convergent and discriminant validity and average variance extracted - Calibration and Validation samples

\begin{tabular}{|c|c|c|c|c|c|c|c|}
\hline Factors (calibration) & CR & AVE & $\mathbf{A M}$ & ER & $\mathbf{I J}$ & ID & IM \\
\hline $\mathrm{AM}$ & .79 & .49 & 1 & - & - & - & - \\
\hline ER & .72 & .39 & $.34^{*}$ & 1 & - & - & - \\
\hline IJ & .78 & .54 & $.01 *$ & $.22 *$ & 1 & - & - \\
\hline ID & .83 & .54 & $.20 *$ & $.02 *$ & $.27^{*}$ & 1 & - \\
\hline IM & .84 & .64 & $.18^{*}$ & $.05^{*}$ & $.14 *$ & $.97 *$ & 1 \\
\hline Factors (validation) & $\mathrm{CR}$ & AVE & $\mathrm{AM}$ & ER & $\mathrm{IJ}$ & ID & IT \\
\hline $\mathrm{AM}$ & .79 & .50 & 1 & - & - & - & - \\
\hline ER & .67 & .34 & $.36^{*}$ & 1 & - & - & - \\
\hline IJ & .73 & .56 & $.02 *$ & $.36^{*}$ & 1 & - & - \\
\hline ID & .82 & .53 & $.15^{*}$ & $<.001 *$ & .31 & 1 & - \\
\hline IM & .70 & .57 & $.13^{*}$ & $.13^{*}$ & $.19 *$ & $.97 *$ & 1 \\
\hline
\end{tabular}

Note. Composite Reliability (CR); Average Variance Extracted (AVE); AM= amotivation; EX= external regulation; IJ= introjected regulation; ID= identified regulation; $\mathrm{IM}=$ intrinsic motivation; * $\left(\mathrm{r}^{2}\right)$.

In the page 7 , Table 4:

\section{Where it was written}

Table 4 Fit indices for the invariance of the measurement model of the PLOCQ in the Portuguese sample across

\begin{tabular}{|c|c|c|c|c|c|c|c|}
\hline & $\chi^{2}$ & df & $\Delta \chi^{2}$ & $\Delta \mathbf{d f}$ & $\mathbf{p}$ & CFI & $\Delta \mathrm{CFI}$ \\
\hline \multicolumn{8}{|l|}{ CS - VS } \\
\hline Configural Invariance & 1033.476 & 250 & - & - & - & .925 & - \\
\hline Measurement Invariance & 1052.619 & 263 & 19.144 & 13 & .119 & .924 & .001 \\
\hline Scale Invariance & 1063.991 & 278 & 30.515 & 28 & .339 & .925 & .000 \\
\hline Residual Invariance & 1113.033 & 296 & 79.557 & 46 & .002 & .922 & .003 \\
\hline \multicolumn{8}{|l|}{$\mathrm{M}-\mathrm{F}$} \\
\hline Configural Invariance & 1009.917 & 250 & - & - & - & .927 & - \\
\hline Measurement Invariance & 1038.488 & 263 & 28.571 & 13 & .008 & .925 & .002 \\
\hline
\end{tabular}




\begin{tabular}{llllllll} 
Scale Invariance & 1060.637 & 278 & 50.720 & 28 & .005 & .924 & .003 \\
Residual Invariance & 1082.785 & 296 & 72.868 & 46 & .007 & .924 & .003 \\
\hline
\end{tabular}

Note. $\chi^{2}=$ chi-squared; $\mathrm{df}=$ degrees of freedom; $\Delta \chi^{2}=$ differences in the value of chi-squared; $\Delta d f=$ differences in the degrees of freedom; CFI $=$ Comparative Fit Index; $\Delta \mathrm{CFI}=$ differences in the value of the Comparative Fit Index

\section{Should read:}

Table 4 Fit indices for the invariance of the measurement model of the PLOCQ in the Portuguese sample across samples, gender, $3^{\text {rd }}$ cycle and secondary cycle

\begin{tabular}{|c|c|c|c|c|c|c|c|}
\hline & $\chi^{2}$ & df & $\Delta \chi^{2}$ & $\Delta \mathbf{d f}$ & $\mathbf{p}$ & CFI & $\Delta \mathbf{C F I}$ \\
\hline \multicolumn{8}{|l|}{ CS - VS } \\
\hline Configural Invariance & 1033.476 & 250 & - & - & - & .925 & - \\
\hline Measurement Invariance & 1052.619 & 263 & 19.144 & 13 & .119 & .924 & .001 \\
\hline Scale Invariance & 1063.991 & 278 & 30.515 & 28 & .339 & .925 & .000 \\
\hline Residual Invariance & 1113.033 & 296 & 79.557 & 46 & .002 & .922 & .003 \\
\hline \multicolumn{8}{|l|}{$M-F$} \\
\hline Configural Invariance & 1009.917 & 250 & - & - & - & .927 & - \\
\hline Measurement Invariance & 1038.488 & 263 & 28.571 & 13 & .008 & .925 & .002 \\
\hline Scale Invariance & 1060.637 & 278 & 50.720 & 28 & .005 & .924 & .003 \\
\hline Residual Invariance & 1082.785 & 296 & 72.868 & 46 & .007 & .924 & .003 \\
\hline \multicolumn{8}{|l|}{ 3rd cycle - secondary cycle } \\
\hline Configural Invariance & 1035.353 & 250 & - & - & - & .924 & - \\
\hline Measurement Invariance & 1063.099 & 263 & 27.746 & 13 & .010 & .923 & .001 \\
\hline Scale Invariance & 1107.665 & 278 & 72.312 & 28 & $<.001$ & .920 & .004 \\
\hline Residual Invariance & 1147.077 & 296 & 111.723 & 46 & $<.001$ & .918 & .006 \\
\hline
\end{tabular}

Note. $\chi^{2}=$ chi-squared; $\mathrm{df}=$ degrees of freedom; $\Delta \chi^{2}=$ differences in the value of chi-squared; $\Delta d f=$ differences in the degrees of freedom; CFI $=\mathrm{Comparative} \mathrm{Fit}$ Index; $\Delta \mathrm{CFI}=$ differences in the value of the Comparative Fit Index; $\mathrm{CS}=$ calibration sample; $\mathrm{VS}=$ validation sample; $\mathrm{F}=$ female sample; $\mathrm{M}=$ male sample

In the page 8:

\section{Where it was written}

Psychometric analysis of the Portuguese version of the PLOCQ showed that the initial hypothesized model (ive factors / 20 items) did not it the pre-deined values adopted in methodology $y^{21,22,23}$. For this matter, individual parameters were analyzed, and two items (intrinsic motivation-14; introjected regulation - 2) were removed because they showed associations with other factors (e.g., the item 2, "Because I want the PE teacher to think I am a good student" presented an association with external regulation).

\section{Should read:}

Psychometric analysis of the Portuguese version of the PLOCQ showed that the initial hypothesized model (five factors / 20 items) did not fit the pre-defined values adopted in methodology $y^{21,22,23}$. For this matter, individual parameters (through the modification indexes) were analyzed, and two items (intrinsic motivation - 14; introjected regulation - 2) were removed because they showed associations with other factors (e.g., the item 2, "Because I want the PE teacher to think I am a good student" presented an association with external regulation). 
In the page 8:

\section{Where it was written}

Deci and Ryan ${ }^{3,30}$ highlight this issue, emphasizing that the SDT constructs underlying the autonomous and controlled motivation types correlate highly among themselves. Several studies in different contexts have reported the same results: exercise ${ }^{36,37}$ and Sport $^{33,34,35}$.

\section{Should read:}

Deci and Ryan ${ }^{3,30}$ highlight this issue, emphasizing that the SDT constructs underlying the autonomous and controlled motivation types correlate highly among themselves. Several studies in different contexts have reported the same results: exercise $\mathrm{e}^{36,37}$ and Sport $^{33,34,35,38,39}$.

In the page 8:

\section{Where it was written}

Thus, considering the assumptions from operationalized multi-group analysis in the methodology ${ }^{21,24}$, it is possible to afirm the following to both samples and gender: i) configural invariance is veriied as the same items group that explains the same factors group is maintained, independently of sample and gender; ii) the factorial weight of the items is equivalent for both samples and gender (measurement invariance), in other words, the items have the same importance regardless of the group; iii) the item intercepts are invariant (equivalents) in both samples and gender, consequently representing scale invariance (i.e., strong invariance). This type of invariance is the most important, because when this assumption is veriied, it means it is legitimate to make results comparisons in different groups, in this case across samples and genders, based on the behavioral regulation, underlying SDT ${ }^{38}$; iv) residual invariance was veriied, because the factorial weights, covariance and error of measurement model operate the same way across samples and genders ${ }^{21,24}$. Thus, these results support PLOCQp use in PE context, as the model presented cross-validation criteria and reveled to be gender invariant, supporting that the theoretical construct underlying the measurement model is interpreted in the same way between male and female students.

\section{Should read:}

Thus, considering the assumptions from operationalized multi-group analysis in the methodology ${ }^{21,24}$, it is possible to affirm the following to both samples, gender, $3^{\text {rd }}$ cycle and secondary cycle: i) configural invariance is verified as the same items group that explains the same factors group is maintained, independently of sample and gender; ii) the factorial weight of the items is equivalent for both samples and gender (measurement invariance), in other words, the items have the same importance regardless of the group; iii) the item intercepts are invariant (equivalents) in both samples and gender, consequently representing scale invariance (i.e., strong invariance). This type of invariance is the most important, because when this assumption is verified, it means it is legitimate to make results comparisons in different groups, in this case across samples and genders, based on the behavioral regulation, underlying SDT ${ }^{40}$; iv) residual invariance was verified, because the factorial weights, covariance and error of measurement model operate the same way across samples and genders ${ }^{21,24}$. Thus, these results support PLOCQp use in PE context, as the model presented cross-validation criteria and reveled to be gender invariant, supporting that the theoretical construct underlying the measurement model is interpreted in the same way between male and female students.

In the page 9:

\section{Where it was written}

Thus, we suggest that future endeavors should try to address this issue for the PE context; ii) in addition to crossvalidation, future studies should focus in longitudinal invariance analysis (e.g., throughout the school year) in order to 
increase the robustness of the instrument; iii) analyze invariance across different age groups (e.g., middle school and high school), to understand if the instrument is interpreted in the same way despite age differences.

\section{Should read:}

Thus, we suggest that future endeavors should try to address this issue for the PE context; ii) in addition to crossvalidation, future studies should focus in longitudinal invariance analysis (e.g., throughout the school year) in order to increase the robustness of the instrument.

In the page 9:

\section{Where it was written}

This issue is particularly important as intrinsic motivation is among the most highlighted factors to the maintenance of behavior over time ${ }^{39}$.

\section{Should read:}

This issue is particularly important as intrinsic motivation is among the most highlighted factors to the maintenance of behavior over time ${ }^{41}$.

In the page 9:

\section{Where it was written}

38. Chen F. What happens if we compare chopsticks with forks? The impact of making inappropriate comparisons in cross-cultural research. J Pers Soc Psychol. 2008; 95: 1005-1018. doi: 10.1037/a0013193

39. Pannekoek L, Piek J, Hagger M. The Children's Perceived Locus of Causality Scale for Physical Education. J Teach Phys Educ. 2014; 33: 162-185. https://doi.org/10.1123/jtpe.2013-0095

\section{Should read:}

38. Monteiro D, Moutão J, Cid, L. Validation of the Behavioral Regulation Sport Questionnaire in Portuguese Athletes. Revista de Psicologia del Desporte, 2018; 27, 145-150

39. Clancy R, Herring M, Campbell M. Motivation Measures in Sport: A Critical Review and Bibliometric Analysis. Frontiers in Psychology, 2017; 8, 1-12. doi: 10.3389/fpsyg.2017.00348

40. Chen F. What happens if we compare chopsticks with forks? The impact of making inappropriate comparisons in cross-cultural research. Journal of Personality and Social Psychology. 2008; 95, 1005-1018. doi: 10.1037/a0013193

41. Pannekoek L, Piek J, Hagger M. The Children's Perceived Locus of Causality Scale for Physical Education. Journal of Teaching in Physical Education. 2014; 33, 162-185. https://doi.org/10.1123/jtpe.2013-0095 